\title{
Thyroid Cancer cM1 TNM Finding v7
}

National Cancer Institute

\section{Source}

National Cancer Institute. Thyroid Cancer CM1 TNM Finding v7. NCI Thesaurus. Code C89160.

Thyroid cancer with distant metastasis. (from AJCC 7th Ed.) 